\title{
Factors counteracting nurses' bullying in healthcare organizations: An applied study in King Abdul-Aziz University Hospital in Jeddah Province
}

\author{
Eman Albishi ${ }^{1}$, Omar Z. Alsharqi*2 \\ ${ }^{1}$ King Faisal Specialist Hospital \& Research Center, Jeddah, Saudi Arabia \\ ${ }^{2}$ Health Services and Hospitals Administration Department, Faculty of Economics and Administration, King Abdulaziz University, \\ Jeddah, Saudi Arabia
}

Received: January 24,2018

DOI: $10.5430 /$ jnep.v8n10p20
Accepted: April 23, 2018

URL: https://doi.org/10.5430/jnep.v8n10p20

Online Published: May 10, 2018

\begin{abstract}
In a time of diminishing human resources in the field of healthcare, bullying among nursing staff is a challenge that has a negative effect on the individual nurse, work team, patient care, and consequently, on the entire healthcare organization. This study aims to investigate the presence of policy that addresses bullying, nurses' knowledge and skills in dealing with bullying behaviour, and the role of nursing managers in counteracting bullying among nurses in the workplace. A quantitative descriptive study utilizing self-administered questionnaires was undertaken. The key results to come out from this study show that the presence of workplace code of ethics policies to address bullying behaviours and the role of nursing managers do not contribute to counteracting bullying among nurses in the selected hospital. However, nurses indicated the significance of knowledge and skills in counteracting bullying. The study conclusions contribute a number of findings of importance to the field of nursing management. The study disclosed significant correlations between the healthcare organization's bullying behaviours policy, managers' roles, and nurses' knowledge and skills in counteracting bullying. Nurses' workplace bullying behaviours can be managed and eradicated by means of the collaboration of the three parties: nurse managers, policy, and nurses' knowledge and skills. This study has considerable implications for nursing management in counteracting bullying among nurses. Managers have a fundamental role in counteracting bullying, for example by setting policy and conducting organization-wide surveys to study nurses' job satisfaction, therefore, recommendations include mandatory peer reviews as part of an annual appraisal for each nurse, the initiation of a formal system to report behavioural issues among healthcare staff and the establishment of a committee to respond to, and deal with, behavioural issues among the organization's staff.
\end{abstract}

Key Words: Nursing bullying, Nursing mobbing, Nurses' lateral violence, Workplace bullying, Bullying policy, Bullying management

\section{INTRODUCTION}

In an era of mounting public demand and rising consumers' expectations, healthcare organizations (HCOs) face increasing competition to provide quality services. Healthy, productive employees are assets that contribute towards the achieve- ment of higher-quality customer services. In that context, the 2008 to 2017 World Health Organization (WHO) global plan of action for workers' health "launched the global framework for healthy workplaces", which emphasized the right of employees to have a physically and psychosocially bullying-

\footnotetext{
${ }^{*}$ Correspondence: Omar Z. Alsharqi; Email: oalsharqi@kau.edu.sa; Address: Health Services and Hospitals Administration Department, Faculty of Economics and Administration, King Abdulaziz University, Jeddah, Saudi Arabia.
} 
free healthy workplace. ${ }^{[1]}$ The WHO's definition of health is "A state of complete physical, mental and social well-being, and not merely the absence of disease". [2] HCOs need to adopt strict management strategies to sustain their employees' physical, mental and psychosocial well-being in order to enable them to retain staff at a time when such organizations worldwide are battling to recruit and attract nurses. A study of the effects of bullying on mental health problems has found the mental effects of bullying can last for up to a year following exposure. ${ }^{[3]}$ Bullying and disruptive behaviours can also be associated with medical errors, leading to preventable adverse outcomes that increase the cost of care. ${ }^{[4]}$ As a result, qualified clinicians and experienced nurses may seek new positions in safer, more professional and respectful HCOs.

Patient satisfaction is derived from best quality and safe care, and is dependent on teamwork, communication, and a collaborative work environment. ${ }^{[5]}$ Workplace bullying is of proven psychosocial risk to nurses' health, work performance, job satisfaction and therefore organizational outcomes. ${ }^{[6]}$ At the organizational level, the need for a comprehensive systematic approach and effective policies is crucial in order to prevent and control the various psychosocial risks at work. ${ }^{[6]}$ The whole organization must therefore be involved to prevent bullying among nurses. The American Nurses Association (ANA) 2015 states in their Code of Ethics for Nurses with Interpretive Statements that nurses are required to "create an ethical environment and culture of civility and kindness, treating colleagues, co-workers, employees, students, and others with dignity and respect." Similarly, nurses must be afforded the same level of respect and dignity as others. ${ }^{[7]}$ To sustain a bullying-free workplace and to promote civility, the management of bullying must be taken in the context of the specific workplace and consider the quality of patient care.

The need for a policy to address workplace bullying received global attention when the Joint Commission (JC) issued a Sentinel Event Alert on the basis of disturbing survey results on the impact of disruptive behaviour on patient safety. The JC developed standards of healthcare leadership and required all HCOs to establish internal policies and procedures (IPPs) in the form of a code of conduct and a procedure to handle and manage disruptive conduct. ${ }^{[8]}$ The critical role of management in planning strategies to deal with bullying consists of educating staff, developing codes of appropriate conduct policy for the workplace, and having a zero-tolerance policy. ${ }^{[9]}$ Safe Work Australia ${ }^{[10]}$ has emphasized the need to eradicate bullying from the workplace, and if this is not possible, the number of incidents and their consequences should be minimized to safeguard nurses' health and safety. Employers have an obligation to provide nurses with a working

Published by Sciedu Press environment that is free from the risk of bullying, and to have written organizational policies and procedures on how to deal with bullying incidents and allegations. ${ }^{[11]}$

Under occupational health and safety legislation, it is the employers' responsibility to take all acceptable operable measures to protect the wellbeing of their staff. The European framework for psychosocial risk management (PRIMA-EF) has developed a framework called the "Macro Policy Level in Psychosocial Risk Management" using European Union (EU) data showing the predominance of psychosocial risks to employees' wellbeing and an intensification of problems such as workplace violence, harassment and bullying. ${ }^{[12]}$ PRIMA-EF aimed to provide a framework for healthcare enterprises' managers to establish policies and procedures at national and organizational levels within the EU. ${ }^{[12]}$ In the USA, the Occupational Safety and Health Administration (OSHA)'s Law and Regulations of workplace bullying considers staff-to-staff bullying a form of violence for which the employer is responsible for the consequences. Therefore, HCOs should be committed to assuming responsibility for assessing the threat of bullying, implementing precautions, and executing solutions. According to the Australian Nursing and Midwifery Federation Law of Workplace Bullying, employers must consult with employees and health and safety representatives to develop and implement a code of ethics and a bullying policy to prevent, and professionally deal with, bullying incidents. ${ }^{[13]}$ Although there have been studies in Saudi Arabian hospitals which revealed that bullying is a serious issue among nursing staff, this study will explore the factors that counteract nurses' bullying in the workplace in King Abdul-Aziz University Hospital, Jeddah Province.

\subsection{Literature review}

Quality and safe patient care are the core missions for all HCOs, and qualified healthy staff are essential to achieving that objective. The majority of healthcare staff are nurses, ${ }^{[14]}$ who are the first-line caregivers. HCOs are keen to attract new nurses and retain qualified ones. Bullying among nurses in the workplace has been recognized as a phenomenon that creates a challenge to HCOs, as bullying negatively influences nurses' health, job satisfaction and intention to stay in an environment where bullying is entrenched, ${ }^{[15]}$ resulting in an increase in healthcare costs. ${ }^{[16]}$ Over the past two decades bullying among nurses has been a concern of researchers in nursing, philosophy and typology, ${ }^{[17-21]}$ viewed as a widespread phenomenon that is damaging to the nursing profession and to the nurses' workplace.

Several terms have been used throughout the literature to conceptualize adverse, abrupt and unacceptable behaviours among nurses in the workplace such as horizon- 
tal violence, ${ }^{[17,22,23]}$ lateral violence, ${ }^{[24,25]}$ lateral hostility, ${ }^{[26]}$ workplace incivility, ${ }^{[27]}$ mobbing, ${ }^{[28]}$ disruptive behaviour ${ }^{[29,30]}$ and bullying. ${ }^{[31-36]}$

The WHO has used the terms bullying and mobbing to conceptualize recurrent vindictive, cruel, or malicious acts occurring over time, in order to humiliate or undermine an individual or group of employees. ${ }^{[37]}$ The term bullying has been used throughout nursing literature to refer to recurrent and intentional behaviours aimed at controlling or causing harm to the target, such as spreading rumours, undermining acts, mocking the victim's personal beliefs or lifestyle, smearing their reputation or degrading their competence, assigning work tasks below their level of competence and training, concealing information that affects their job performance, ignoring them, social exclusion, public shaming, and making verbal and nonverbal threats. ${ }^{[38]}$ Bullying may include subtle and covert behaviours and not just physical violence. ${ }^{[19]}$ Workplace bullying is characterised by persistent negative behaviours that cause psychological harm to the target, such as harassing, insulting, socially excluding or adversely affecting the work of the target. ${ }^{[39]}$ There are three ways that bullies usually attack their targets. Victims may suffer personal attacks such as intimidation, and social isolation. They may also be attacked professionally, for example, the bully may undermine their competencies, or limit career opportunities. Their work tasks may also be impacted by means such as hiding valuable information, making work difficult to accomplish. ${ }^{[21]}$

Bullying has been recognized worldwide as being significantly prevalent in nurses' workplaces. A Spanish study found that bullying among nurses was reported daily or weekly. ${ }^{[40]}$ A United Kingdom study reported that $44 \%$ of participants were subjected to one or more types of bullying behaviour in the previous year, and $50 \%$ of the participants reported witnessing an incident of bullying against another nurse. ${ }^{[41]}$ Studies of workplace bullying in Saudi Arabia indicated a significant prevalence of bullying among staff nurses and nursing students. ${ }^{[42]}$ A Cincinnati study of "Novice Nurse Productivity Following Workplace Bullying" found that more than $50 \%$ of registered nurses who responded had experienced bullying on a daily basis. ${ }^{[43]}$ A recent USA study revealed that $53 \%$ of participants reported bullying by their co-workers. ${ }^{[4]}$ This is consistent with a previous study in the USA, in which $24 \%$ of nurses reported bullying by senior nurse colleagues, $17 \%$ by charge nurses and $14 \%$ by nursing managers. ${ }^{[45]}$

Bullying was identified as a global issue and considered to be an act of violence by the report of the Joint Programme on Workplace Violence in the Health Sector by the International
Labour Office (ILO), the International Council of Nurses (ICN), the WHO, and Public Services International (PSI), and their research indicated the high prevalence of bullying as well as other types of workplace violence. ${ }^{[37]}$ Turkish national research on workplace violence revealed that $24 \%$ of nursing staff had been bullied. ${ }^{[46]}$ An Australian study of workplace violence in healthcare sector staff revealed that nurses have the highest incidence of bullying when compared to other healthcare staff in the same study. ${ }^{[47]}$

\subsubsection{The effect of bullying on nurses and organizations}

A review of the literature concerning the effect of the workplace on nurses' health and wellbeing showed that bullying has tremendous consequences for nurses' health and job outcomes. Australian qualitative study data revealed that some bullying behaviours were motivated by malice. This finding shows the negative consequences on work productivity and staff turnover. $^{[47]}$ The long-term effects of bullying cause bullied nurses to have lower job satisfaction, greater levels of anxiety and depression, and a tendency to leave the organization or their current position. ${ }^{[41,48]}$ A qualitative study of female nursing students from a governmental university in Saudi Arabia revealed that horizontal violence and harassment in clinical placements caused negative psychological signs such as anger, reality shock, insecurity, helplessness, a sense of inferiority, sadness and crying, anxiety, and panic. It found that students could lose their motivation for learning, have negative ideas toward the profession, and have doubts about their choice of nursing as a career, leading to an increase in absenteeism, and an unwillingness to communicate with the bully or to return to the same unit. ${ }^{[42]}$ Similarly, Reknes' study ${ }^{[49]}$ showed that the mental health effects of bullying could last for as long as one year after exposure. Nurses reported that bullying had a negative personal and professional impact on them, and those who had been bullied were three times more likely to report an intention to leave their current workplace than nurses who had never been bullied. ${ }^{[50]}$

Furthermore, the turnover of nurses and rates of absenteeism increased in workplaces where bullying behaviours were embedded. There is also a negative impact on the organization in the form of a reduction in productivity as well as the loss of hard-to-replace nurses. ${ }^{[18]}$ The consequences of these behaviours are far-reaching and include an increase in costs to the $\mathrm{HCO}$, the resignation of experienced nurses, a failure to attract experienced nurses, and damage to the organization's reputation. ${ }^{[51]}$ The consequences of bullying should be considered as an issue for the entire organization and not simply as a problem for the targeted nurse. Organizational failure to formally address bullying and resolve its issues and consequences could be due to the existence 
of alliances of bullies who misuse their positions of power within the organization. ${ }^{[48,52]}$ When the nursing direct managers, supervisors, or charge nurses misuse their position by bullying, ${ }^{[45,48]} \mathrm{HCO}$ management must address behavioural issues and evaluate their success. ${ }^{[33]}$ Furthermore, bullying could have an impact on the organization by adversely affecting patient satisfaction and the quality and outcomes of care, and result in rising tensions in patient care areas, reduced performance of nursing staff, resignations and increasing costs. ${ }^{[5,44,53,54]}$

\subsubsection{The need for a workplace bullying policy}

Since 2002, the WHO has identified workplace bullying in healthcare as violent behaviour that undermines health workforces' retention. As a consequence, the ILO/ICN/WHO/PSI joint programme has designed guidelines emphasizing the importance of an official workplace policy to address behavioural issues and other violent behaviours. ${ }^{[37]}$ The consequences of workplace bullying became a cause of concern, and a global call was raised to establish an anti-bullying policy. ${ }^{[55]}$ A formal written policy promoting a zero-tolerance approach to workplace bullying is critical in order to counteract bullying behaviours and maintain a healthy workplace environment for nurses. ${ }^{[52,56,57]}$ This global concern means that HCOs seeking accreditation are now compelled to establish a code of conduct policy to address behavioural issues and to educate the organization's staff about all aspects of the policy. ${ }^{[30]}$ The ANA has emphasized that a proactive approach to prevent workplace bullying and other violent behaviour is critical in order to ensure the safety of staff and patients. ${ }^{[58]}$ The PRIMA-EF and Australian Nursing and Midwifery Federation emphasized the need to develop legislation to manage violent workplace behaviours. ${ }^{[12,13]}$

In order for a written policy to be effective in preventing and resolving workplace behavioural issues, it must precisely differentiate staff roles, clearly distinguish bullying from harassment and physical violence, have detailed steps that are easy to implement, and be accessible to all of the organization's staff. ${ }^{[59,60]}$ At a time when the healthcare workforce is declining, a hostile working environment will not contribute to the retention of staff. ${ }^{[18]}$ The involvement of upper management is essential, since the literature shows that direct nursing managers are highly implicated in the bullying of their staff. ${ }^{[45,48,50,61,62]}$ Higher management commitment to the resolution of behavioural issues among HCO staff is therefore essential. ${ }^{[18]}$ This includes management encouragement of the staff to report bullying, the promotion of staff confidence in the efficacy of the reporting system and the development and evaluation of a zero-tolerance policy of unacceptable workplace behaviour. ${ }^{[57]}$

Published by Sciedu Press
The presence of a workplace bullying policy is not enough to ensure the efficacy of the existing policy and the preventive system; management monitoring and workplace surveys to detect bullying behaviour also play significant roles. ${ }^{[52,56]}$ Nursing management must improve nurses' leadership skills so that they can address the issue of workplace bullying behaviours and how to resolve them. ${ }^{[62]}$ Nursing management and leaders are obligated to counteract bullying through the enforcement of transparent and accountable practices in order to create workplace processes that foster positive systems, justice and respect, ${ }^{[52]}$ promote staff nurses' knowledge about the workplace behaviour policy, reinforce group collaboration, resolve conflict, ${ }^{[53]}$ foster a culture of teamwork, display an interest in the professional development of their staff, support their staff in daily work conflicts, and empower staff by considering their inputs and rewarding them. ${ }^{[62]}$ Hutchinson et al. ${ }^{[20]}$ proposed a model of "antecedents and consequences of workplace bullying" which indicated that organizational alliances who misuse their powers participated in the normalization of bullying. The model provides an insight for higher management by highlighting the organizational characteristics that are antecedent to bullying behaviours. The three parties involved in counteracting nurses' workplace bullying are the nursing staff, their immediate supervisor and higher management, by means of disseminating respect and collaboration, demonstrating a proactive leadership approach, and providing resources and setting strategies respectively. ${ }^{[36]}$

Several studies of nurses' workplace bullying have highlighted the role of nursing management in counteracting bullying by means of providing education to staff nurses in how to deal with behavioural issues. ${ }^{[35,36,57,63]}$ The prevalence of unacceptable behaviours has significantly declined as a result of increasing nurses' knowledge of hospital policies regarding acceptable and unacceptable behaviours. ${ }^{[23]}$ Some nurses perceive workplace behavioural issues as a part of their job that they cannot resolve, hence the majority of behavioural incidents go unreported. ${ }^{[2]}$ The education and training of nurses is therefore a primary step in changing this perception in order to counteract behavioural issues. ${ }^{[64]}$ Nurses who were bullied, or witnessed bullying toward others, recommended the implementation of education and training programs as a solution. ${ }^{[22,24,50]}$ The Lin training program for nurses which promoted assertiveness, self-esteem, and interpersonal communication showed a significant improvement in nurses' assertiveness and selfesteem. ${ }^{[65]}$ The structured feedback programme appears to have improved healthcare workers' awareness of the threat of violence. ${ }^{[66]}$ Methods such as the development of skills to deal with confrontation ${ }^{[24]}$ and training in assertiveness and curbing aggression ${ }^{[35]}$ have also been shown to limit bullying. 
Griffin $^{[24]}$ demonstrated that cognitive rehearsal teaching to newly-licensed nurses working in critical care helped them to confront their bullies and resolve behavioural issues. The education of nursing managers and administrators to be aware of personal and organizational aspects that influence bullying is vital in both the resolution and prevention of bullying issues. ${ }^{[67]}$

\subsection{Significance of the study}

HCOs must address the issues of behaviours that threaten the performance of healthcare staff in order to achieve the best quality work performance and to encourage a culture of safety. The identification of the factors which could counteract bullying among nurses in one HCO can establish standards to compare that organization to others that have similar tasks. This allows HCOs to relate their practices to others in the industry sector. There are a number of factors to consider:

- Employers have applied national laws to their workplaces IPPs. There is a need for IPPs to address acceptable \& expected workplace behaviours to ensure efficient and effective intervention.

- Nurses' leaders play a significant role in battling workplace bullying as they are the founders of the work group culture. HCO managers must have all the necessary resources to alleviate the consequences of employee-to-employee bullying.

- It is more effective and efficient to shield nurses from bullying by developing and improving their knowledge and skills in handling bullying situations than it is to simply help the victim.

- Identifying demographic variances in response to each variable will accentuate the understanding of response differences.

\subsection{Research objective}

To investigate the presence of a workplace bullying policy, the nursing manager's role, and the knowledge and skills of nursing staff as factors which can counteract and eradicate bullying among nursing staff in HCOs, and to identify the demographic differences in responses to each variable.

\subsection{Research hypotheses}

- There is a significant statistical relationship between the presence of a workplace code of ethics policy to address bullying and the prevalence of bullying among nurses in the workplace.

- There is a significant statistical relationship between the nursing manager's role in handling bullying issues and the prevalence of bullying among nurses in the workplace.
- There is a significant statistical relationship between the knowledge and skills of nursing staff in dealing with and confronting bullying and its effects, and the prevalence of bullying among nurses in the workplace.

\section{METHOD}

\subsection{Research design}

The descriptive analytical method provides researchers with a consistent understanding and summary of a large set of complex data. Several studies have used this method to identify the extent of workplace bullying, ${ }^{[61]}$ and to examine the relationship between the nurses' workplace and bullying. ${ }^{[68]}$ Descriptive survey has been used to assess nurses' perception about workplace bullying. ${ }^{[33,35]}$ Yildirım ${ }^{[15]}$ used descriptive statistics utilizing questionnaires to assess Turkish nurses' workplace bullying and its effects. In this research, descriptive analytical methods were used to provide numerical data to identify the statistical relationship between the independent and dependent variables in order to confirm the correlation in the research hypothesis. Researchers have applied descriptive statistics to measure participants' pre- and postintervention responses. ${ }^{[6]}$ Quantitative research has been defined as a broad umbrella which objectively and formally examines a relationship between variables. ${ }^{[70]}$ A quantitative approach was therefore selected. This approach aimed to investigate the presence of a workplace code of conduct policy to address bullying behaviours, the role of nursing managers, and the knowledge and skills of nursing staff as factors which could counteract and eradicate bullying among nursing staff in King Abdul-Aziz University Hospital. A descriptive analytical cross-sectional survey employing selfadministered questionnaires was conducted to collect data on factors affecting the bullying of nurses in this hospital. The primary data tool was the questionnaires which were distributed to all nurses' managers and nursing staff, which were used in conjunction with secondary resources such as books, journals, statistics and web pages.

\subsection{Research population and sample}

It was recognized that there is a high prevalence of bullying and disruptive behaviours among nurses in HCOs, however, there is no published study identifying the factors that mitigate bullying among nurses in Saudi Arabia. For that reason, the intended populations were the managers of each nursing department, the nursing manager of the organization, nursing supervisors and nursing staff in King Abdul Aziz University Hospital.

The research population consisted of 1,086 nurses. The sample consisted of 286 hospital nursing managers and staff. The sample type was a quota stratified random sample. The 
inclusion criteria for the sample were: all nurses holding a management position, the head nurse of each department, nursing supervisors, and registered nurses. Nursing students were excluded from the sample. Nursing students were excluded because they only work in a particular nursing unit for a short period of time, which is insufficient to satisfy the sample criteria.

\subsection{Data collection tools and techniques}

The study tool was based on the literature review, and was a questionnaire developed using multiple resources, including the questionnaire developed by the parties of the "Joint Program on Workplace Violence in the Health Sector", ${ }^{[71]}$ which was revised to fit the research sample. The original questionnaire has been used by several countries ${ }^{[71-74]}$ and their research has been published on the WHO official web site under the global program of Workplace Violence in the Health Sector.

In addition, the study used published data from qualitative research studies as follows: the strategies to counteract bullying, including the role of the immediate supervisor, coworkers and upper management in imposing a humanistic value system against bullying and raising awareness of bullying, ${ }^{[36]}$ an interview studying nurse managers' interpretation and implementation of the workplace bullying policy; ${ }^{[59,60]} \mathrm{a}$ report of Australian sequential qualitative studies that identified immediate and higher management roles as important in mitigating against bullying behaviours ${ }^{[48]}$ and an exploratory design with an applied intervention study which showed that an overwhelming majority $(96 \%)$ of registered nurses recommended that all hospital nurses should be educated about workplace lateral violence. ${ }^{[24]}$

The questionnaire was divided into four sections. The first section gathered demographic information about the participant's gender, nationality, working hours, nursing qualifications, current job title, and years of experience in both nursing and their current position. The second section utilized Likert scale questions to identify the nurses' knowledge and skills in dealing with bullying behaviours. The third part identified the role of managers in dealing with and preventing bullying among nursing staff, and the fourth part examined staff nurses' knowledge about dealing with bullying in the workplace.

\section{Results}

\subsection{Demographic data}

As shown in Table 1, the majority of respondents $(84.8 \%)$ are female, while the rest $(15.2 \%)$ are male. About $48.6 \%$ of the respondents are Filipinos, $31.4 \%$ are Indians, $18.9 \%$ are Saudis, $0.7 \%$ are other Arabic nationalities, and only

Published by Sciedu Press
$0.3 \%$ are western. The majority $(96.6 \%)$ of the respondents work full time, while only $3.4 \%$ are part time. Table 1 also shows that $70.6 \%$ of the respondents have a Bachelor's degree in nursing, $26.7 \%$ have a Diploma in nursing, $2.4 \%$ have a Master's degree in nursing, while only $0.3 \%$ have a $\mathrm{PhD}$ in nursing. The majority $(74 \%)$ of the respondents are staff nurses, $12.2 \%$ are head nurse assistants, $5.1 \%$ are nurse managers, $4.4 \%$ are head nurses and $4.4 \%$ are nursing supervisors. $33.8 \%$ have more than 10 years in nursing, $20.9 \%$ have $7-10$ years, $39.9 \%$ have $3-6$ years, while only $5.4 \%$ have less than 3 years in the nursing profession. It is also shown that $33.7 \%$ of the respondents have less than 3 years in the current position, $31.1 \%$ have 3-6 years, $26 \%$ have $7-10$ years, and only $9.1 \%$ have more than 10 years in the current position.

\subsection{Research variables analysis}

Table 2 shows the weighted means and standard deviations, and the results of the $\chi^{2}$ test of goodness-of-fit for each statement of the axis "Workplace bullying policy in your hospital". The means range from 3.15 to 2.52 and the overall mean is 2.71, which indicates "Unsure". The highest mean (3.15) was reported for item 8 (There is a code of conduct policy addressing bullying as an ethical issue among healthcare organization [HCO] staff), indicating the answer "Unsure", and the lowest mean (2.52) was reported for item 14 (The written bullying policy is accessible to you), indicating the answer "Unsure". We find that all $\chi^{2}$ values are statistically significant ( $p$-values are less than .05), i.e., there is a significant difference between the expected and observed frequencies. In other words, there is a significant difference between the respondents in their opinion toward each statement of the axis "Workplace bullying policy in your hospital".

Table 3 shows the weighted means and standard deviations, and the results of the $\chi^{2}$ test of goodness-of-fit for each statement of the axis "Nurses' knowledge and skills in handling bullying". The means range from 4.32 to 1.65 and the overall mean is 2.84 , which indicates "Unsure". The highest mean (4.32) was reported for item 29 (Formal structured education and training are important in counteracting bullying incidents), indicating the answer "Strongly Agree", and the lowest mean (1.65) was reported for item 18 (I have received formal structured education and training in how to face and/or handle a workplace bullying situation), indicating the answer "Unsure". We find that all $\chi^{2}$ values are statistically significant ( $p$-values are less than .05), i.e., there is a significant difference between the expected and observed frequencies. In other words, there is a significant difference between the respondents in their opinion toward each statement of the axis "Nurses' knowledge and skills in handling bullying". 
Table 1. Descriptive statistic frequencies and percentages for demographic data $(\mathrm{N}=296)$

\begin{tabular}{|c|c|c|c|}
\hline Variables & Variable distribution & Frequency & Percentage (\%) \\
\hline \multirow{2}{*}{ What is your gender? } & Male & 45 & 15.2 \\
\hline & Female & 251 & 84.8 \\
\hline \multirow{7}{*}{ Which category best describes you? } & Saudi Arabian & 56 & 18.9 \\
\hline & Other Arabic nationality & 2 & 0.7 \\
\hline & Filipino & 144 & 48.6 \\
\hline & Indian & 93 & 31.4 \\
\hline & Western nationality & 1 & 0.3 \\
\hline & North American & 0 & 0 \\
\hline & Other & 0 & 0 \\
\hline \multirow{2}{*}{ Working hours. } & Full time & 286 & 96.6 \\
\hline & Part time & 10 & 3.4 \\
\hline \multirow{4}{*}{$\begin{array}{l}\text { What is the highest level of your } \\
\text { nursing qualification? }\end{array}$} & Diploma in nursing & 79 & 26.7 \\
\hline & Bachelor's degree in nursing & 209 & 70.6 \\
\hline & Master's degree in nursing & 7 & 2.4 \\
\hline & $\mathrm{PhD}$ in nursing & 1 & 0.3 \\
\hline \multirow{5}{*}{ What is your current position? } & Nurse manager & 15 & 5.1 \\
\hline & Head nurse & 13 & 4.4 \\
\hline & Nursing supervisor & 13 & 4.4 \\
\hline & Head nurse assistant & 36 & 12.2 \\
\hline & Staff nurse & 219 & 74.0 \\
\hline \multirow{4}{*}{$\begin{array}{l}\text { How many years of experience do } \\
\text { you have in nursing? }\end{array}$} & $<3$ years. & 16 & 5.4 \\
\hline & 3-6 years & 118 & 39.9 \\
\hline & 7-10 years & 62 & 20.9 \\
\hline & $>10$ years & 100 & 33.8 \\
\hline \multirow{4}{*}{$\begin{array}{l}\text { How many years of experience do } \\
\text { you have in your current position? }\end{array}$} & $<3$ years. & 100 & 33.7 \\
\hline & 3-6 years & 92 & 31.1 \\
\hline & 7-10 years & 77 & 26.0 \\
\hline & $>10$ years & 27 & 9.1 \\
\hline
\end{tabular}

Table 2. Workplace bullying policy in your hospital

\begin{tabular}{|c|c|c|c|c|c|c|c|}
\hline No. & Items & $\begin{array}{l}\text { Weighted } \\
\text { mean }\end{array}$ & SD. & $\begin{array}{l}\text { Chi- } \\
\text { square }\end{array}$ & $p$ & Rank & $\begin{array}{l}\text { Totally } \\
\text { agree }\end{array}$ \\
\hline 8 & $\begin{array}{l}\text { There is a code of conduct policy addressing bullying as an } \\
\text { ethical issue among healthcare organization (HCO) staff. }\end{array}$ & 3.15 & 1.12 & 71.94 & .000 & 1 & Unsure \\
\hline 11 & $\begin{array}{l}\text { The bullying policy steps are clear and easy to use and } \\
\text { implement. }\end{array}$ & 2.79 & 0.81 & 284.17 & .000 & 2 & Unsure \\
\hline 10 & The bullying policy is written in clear language. & 2.76 & 0.85 & 227.11 & .000 & 3 & Unsure \\
\hline 12 & $\begin{array}{l}\text { The bullying policy clearly differentiates bullying from } \\
\text { other physically violent behaviours and harassment. }\end{array}$ & 2.69 & 0.75 & 332.75 & .000 & 4 & Unsure \\
\hline 13 & $\begin{array}{l}\text { The bullying policy clearly identifies improper, } \\
\text { unacceptable, and acceptable conduct. }\end{array}$ & 2.68 & 0.75 & 339.68 & .000 & 5 & Unsure \\
\hline 15 & $\begin{array}{l}\text { There is a formal system for reporting bullying incidents } \\
\text { among HCO staff. }\end{array}$ & 2.68 & 0.80 & 232.72 & .000 & 6 & Unsure \\
\hline 17 & The bullying policy is revised regularly. & 2.68 & 0.74 & 376.23 & .000 & 7 & Unsure \\
\hline 16 & $\begin{array}{l}\text { There is a bullying victims support group or counselling } \\
\text { program. }\end{array}$ & 2.59 & 0.76 & 270.62 & .000 & 8 & Disagree \\
\hline 9 & There is a policy addressing bullying among HCO staff. & 2.58 & 1.14 & 83.36 & .000 & 9 & Disagree \\
\hline \multirow[t]{2}{*}{14} & The written bullying policy is accessible to you. & 2.52 & 0.83 & 210.12 & .000 & 10 & Disagree \\
\hline & Overall workplace bullying policy in your hospital & 2.71 & & & & & Unsure \\
\hline
\end{tabular}


Table 3. Nurses' knowledge and skills in handling bullying

\begin{tabular}{|c|c|c|c|c|c|c|c|}
\hline No. & Items & $\begin{array}{l}\text { Weighted } \\
\text { mean }\end{array}$ & SD. & $\begin{array}{l}\text { Chi- } \\
\text { square }\end{array}$ & $p$ & Rank & $\begin{array}{l}\text { Totally } \\
\text { agree }\end{array}$ \\
\hline 29 & $\begin{array}{l}\text { Formal structured education and training are important in } \\
\text { counteracting bullying incidents. }\end{array}$ & 4.32 & 1.07 & 385.7 & .000 & 1 & $\begin{array}{l}\text { Strongly } \\
\text { Agree }\end{array}$ \\
\hline 28 & $\begin{array}{l}\text { I did not report or tell anyone about the bullying incident, } \\
\text { because I do not trust that proper action will be taken. }\end{array}$ & 3.65 & 1.31 & 109.8 & .000 & 2 & Agree \\
\hline 24 & The bullying incident could have been prevented. & 3.40 & 0.87 & 218.7 & .000 & 3 & Agree \\
\hline 22 & When I was bullied, I confronted the bully to defend myself. & 3.39 & 1.10 & 244.7 & .000 & 4 & Unsure \\
\hline 30 & I seek education about how to deal with workplace bullying. & 3.31 & 1.13 & 134.6 & .000 & 5 & Unsure \\
\hline 23 & I supported a colleague who was bullied. & 3.25 & 1.01 & 149.5 & .000 & 6 & Unsure \\
\hline 26 & $\begin{array}{l}\text { I did not report or tell anyone about the bullying incident, } \\
\text { because I was afraid of negative consequences. }\end{array}$ & 3.24 & 1.38 & 36.5 & .000 & 7 & Unsure \\
\hline 27 & $\begin{array}{l}\text { I did not report or tell anyone about the bullying incident, } \\
\text { because I did not know who to report it to. }\end{array}$ & 2.37 & 1.30 & 149.5 & .000 & 8 & Unsure \\
\hline 21 & $\begin{array}{l}\text { I encouraged a colleague who was bullied to report the } \\
\text { incident through the proper channel. }\end{array}$ & 2.26 & 1.24 & 126.1 & .000 & 9 & Unsure \\
\hline 19 & When I was bullied I reported it through the proper channel. & 2.13 & 1.14 & 117.3 & .000 & 10 & Unsure \\
\hline 20 & $\begin{array}{l}\text { When I witnessed another nurse being bullied I reported it } \\
\text { through the proper channel. }\end{array}$ & 2.02 & 1.06 & 161.2 & .000 & 11 & Unsure \\
\hline 25 & $\begin{array}{l}\text { I did not report or tell anyone about the bullying incident, } \\
\text { because it was not important. }\end{array}$ & 1.91 & 1.11 & 197.1 & .000 & 12 & Unsure \\
\hline \multirow[t]{2}{*}{18} & $\begin{array}{l}\text { I have received formal structured education and training in } \\
\text { how to face and/or handle a workplace bullying situation. }\end{array}$ & 1.65 & 0.85 & 303.1 & .000 & 13 & Unsure \\
\hline & Overall nurses' knowledge and skills in handling bullying. & 2.84 & & & & & Unsure \\
\hline
\end{tabular}

Table 4 shows the weighted means and standard deviations, and the results of the chi-square test of goodness-of-fit for each statement of the axis "Nursing manager's role in handling bullying situations". The means range from 4.10 to 1.82 and the overall mean is 2.66 , which indicates "Unsure". The highest mean (4.10) was reported for item 31 (Giving equal opportunities in learning and professional development could contribute to reducing bullying incidents), indicating the answer "Agree", and the lowest mean (1.62) was reported for item 40 (There is always managerial encouragement to report bullying incidents), indicating the answer "Disagree". We find that all chi-square values are statistically significant ( $p$-values are less than .05), i.e., there is a significant difference between the expected and observed frequencies. In other words, there is a significant difference between the respondents in their opinion toward each statement of the axis "Nursing manager's role in handling bullying situations".

Table 5 shows the weighted means and standard deviations, and the results of the chi-square test of goodness-of-fit for each statement of the axis "Bullying". The means range from 4.51 to 3.55 and the overall mean is 4.12 , which indicates "Agree". The highest mean (4.51) was reported for item 44 (Bullying could take several forms such as intimidating gestures, undermining acts, verbal affront, improper work in- terference, withholding information, social isolation, smearing professional or personal reputations, and being given an unmanageable work load), indicating the answer "Strongly Agree", and the lowest mean (3.55) was reported for item 49 (Healthcare organizations where bullying among nurses is embedded have difficulties in retaining new nurses and lose expert nurses), indicating the answer "Agree". We find that all chi-square values are statistically significant ( $p$-values are less than .05), i.e., there is a significant difference between the expected and observed frequencies. In other words, there is a significant difference between the respondents in their opinion toward each statement of the axis "Bullying".

\subsubsection{The differences between demographic variables in axes}

Table 6 shows the results of the independent samples $t$-test. This is performed to test the differences between respondents in their opinions toward each axis according to gender. The results show the following:

There are statistically significant differences between male and female nurses in their opinions toward the axis "Nurses' knowledge and skills in handling bullying situations" since the $p$-value is less than .05 , and the mean is higher for male nurses, i.e. male nurses have a more positive opinion to- 
ward 'Nurses' knowledge and skills in handling bullying situations" than female nurses.

There are no statistically significant differences between male and female nurses in their opinion toward each of the axes "Workplace bullying policy in your hospital", "Nursing manager's role in handling bullying situations" and "Bullying", since the $p$-values are greater than .05 .

Table 4. Nursing manager's role in handling bullying situations

\begin{tabular}{|c|c|c|c|c|c|c|c|}
\hline No. & Items & $\begin{array}{l}\text { Weighted } \\
\text { mean }\end{array}$ & SD. & $\begin{array}{l}\text { Chi- } \\
\text { square }\end{array}$ & $p$ & Rank & $\begin{array}{l}\text { Totally } \\
\text { agree }\end{array}$ \\
\hline 31 & $\begin{array}{l}\text { Giving equal opportunities in learning and professional } \\
\text { development could contribute to reducing bullying incidents. }\end{array}$ & 4.10 & 0.79 & 151.2 & .000 & 1 & Agree \\
\hline 41 & $\begin{array}{l}\text { A mandatory peer review system could contribute to a } \\
\text { reduction in bullying incidents. }\end{array}$ & 4.09 & 0.93 & 200.4 & .000 & 2 & Agree \\
\hline 34 & $\begin{array}{l}\text { My manager uses a passive approach when handling a bullying } \\
\text { situation. }\end{array}$ & 3.71 & 0.70 & 446.9 & .000 & 3 & Agree \\
\hline 32 & $\begin{array}{l}\text { When my colleague or I reported a bullying incident, my } \\
\text { manager took action to investigate it. }\end{array}$ & 2.73 & 0.95 & 168.9 & .000 & 4 & Unsure \\
\hline 36 & $\begin{array}{l}\text { My nursing manager creates a strong sense of teamwork } \\
\text { between staff. }\end{array}$ & 2.55 & 0.96 & 139.9 & .000 & 5 & Disagree \\
\hline 33 & $\begin{array}{l}\text { My manager uses a proactive approach in handling a bullying } \\
\text { situation. }\end{array}$ & 2.42 & 0.84 & 253.6 & .000 & 6 & Disagree \\
\hline 37 & $\begin{array}{l}\text { My nursing manager is highly involved in the day-to-day } \\
\text { issues and work processes on the unit. }\end{array}$ & 2.26 & 0.93 & 244.8 & .000 & 7 & Disagree \\
\hline 38 & $\begin{array}{l}\text { Nursing managers are empowering staff nurses by asking for } \\
\text { input and making decisions based on staff feedback. }\end{array}$ & 2.16 & 1.06 & 152.0 & .000 & 8 & Disagree \\
\hline 35 & $\begin{array}{l}\text { I am satisfied with the way my manager is handling bullying } \\
\text { issues. }\end{array}$ & 2.05 & 0.96 & 176.8 & .000 & 9 & Disagree \\
\hline 39 & $\begin{array}{l}\text { All nursing staff are given equal learning and professional } \\
\text { development opportunities by their managers. }\end{array}$ & 2.02 & 0.93 & 190.7 & .000 & 10 & Disagree \\
\hline 42 & $\begin{array}{l}\text { Upper management always shows commitment to resolving } \\
\text { bullying issues among nurses. }\end{array}$ & 2.02 & 1.14 & 156.5 & .000 & 11 & Disagree \\
\hline \multirow[t]{2}{*}{40} & $\begin{array}{l}\text { There is always managerial encouragement to report bullying } \\
\text { incidents. }\end{array}$ & 1.82 & 0.98 & 118.5 & .000 & 12 & Disagree \\
\hline & Nursing manager's role in handling bullying situations & 2.66 & & & & & Unsure \\
\hline
\end{tabular}

\subsubsection{Relationship between independent and dependent variables}

It is clear from Table 7 that the model of multiple regressions of the factors (independent variables) on the dependent variable (Bullying) in general is significant since the sig. is 0.018 , and that the factors as a whole contribute to $3.4 \%$ of the dependent variable (Bullying). The results show that both "Nurses' knowledge and skills in handling bullying situations" and "Nursing manager's role in handling bullying situations" have a significant impact on the dependent variable (Bullying) since their $p$-values are less than .05, but the axis "Workplace bullying policy in your hospital" has no significant impact on the dependent variable (Bullying). The following equation represents the relationship (regression model) between the independent variables (factors) and the dependent variable (Bullying): $\mathrm{y}=43.911+0.023 \mathrm{X}_{1}+$ $0.149 \mathrm{X}_{2}-0.133 \mathrm{X}_{3}$.
The findings from Table 8 are as follows:

1) There is a significantly statistical relationship between establishing a workplace code of ethics policy to address bullying behaviours and bullying among nurses in the workplace. The relationship between "Workplace bullying policy in your hospital" and "Bullying". We find that the correlation coefficient is 0.082 , which indicates an inverse relationship, as the lack of an effective and efficient policy contributes directly to an increase in nurses' workplace bullying and its negative effects.

The $p$-value is .159 which is not statistically significant, so we reject the first hypothesis, i.e., there is no statistically significant relationship between the presence of a workplace code of ethics policy to address bullying behaviours and counteracting bullying among nurses in the workplace. Figure 1 represents such a relationship. 
Table 5. Bullying

\begin{tabular}{|c|c|c|c|c|c|c|c|}
\hline No. & Items & $\begin{array}{l}\text { Weighted } \\
\text { mean }\end{array}$ & SD. & $\begin{array}{l}\text { Chi- } \\
\text { square }\end{array}$ & $p$ & Rank & $\begin{array}{l}\text { Totally } \\
\text { agree }\end{array}$ \\
\hline 44 & $\begin{array}{l}\text { Bullying could take several forms such as intimidating gestures, } \\
\text { undermining acts, verbal affront, improper work interference, } \\
\text { withholding information, social isolation, smearing professional or } \\
\text { personal reputations, and being given an unmanageable work load. }\end{array}$ & 4.51 & 0.71 & 403.6 & .000 & 1 & $\begin{array}{l}\text { Strongly } \\
\text { Agree }\end{array}$ \\
\hline 43 & $\begin{array}{l}\text { Bullying is mistreatment intended to cause harm or damage to the } \\
\text { targeted nurse. }\end{array}$ & 4.39 & 0.98 & 385.2 & .000 & 2 & $\begin{array}{l}\text { Strongly } \\
\text { Agree }\end{array}$ \\
\hline 52 & $\begin{array}{l}\text { Treating bullying behaviours as normal behaviour could result in an } \\
\text { unhealthy work environment. }\end{array}$ & 4.36 & 0.66 & 201.5 & .000 & 3 & $\begin{array}{l}\text { Strongly } \\
\text { Agree }\end{array}$ \\
\hline 53 & $\begin{array}{l}\text { Bullying behaviours could become normalized and viewed as } \\
\text { legitimate within the organizational culture. }\end{array}$ & 4.36 & 0.70 & 194.9 & .000 & 4 & $\begin{array}{l}\text { Strongly } \\
\text { Agree }\end{array}$ \\
\hline 51 & $\begin{array}{l}\text { Bullying could be a misuse of power, such as managerial bullying of } \\
\text { staff. }\end{array}$ & 4.35 & 0.70 & 180.6 & .000 & 5 & $\begin{array}{l}\text { Strongly } \\
\text { Agree }\end{array}$ \\
\hline 54 & $\begin{array}{l}\text { Fostering a culture of respect and promoting teamwork can mitigate } \\
\text { bullying behaviours. }\end{array}$ & 4.26 & 0.89 & 275.8 & .000 & 6 & $\begin{array}{l}\text { Strongly } \\
\text { Agree }\end{array}$ \\
\hline 45 & $\begin{array}{l}\text { Bullying has a negative effect on the individual's mental, physical } \\
\text { and psychological wellbeing. }\end{array}$ & 4.14 & 0.55 & 171.3 & .000 & 7 & Agree \\
\hline 47 & $\begin{array}{l}\text { If bullying is not stopped it could become embedded in the work } \\
\text { environment and become regular behaviour. }\end{array}$ & 4.14 & 0.77 & 117.8 & .000 & 8 & Agree \\
\hline 46 & Bullying negatively influences the entire work environment. & 4.06 & 0.61 & 331.2 & .000 & 9 & Agree \\
\hline 48 & $\begin{array}{l}\text { Bullying among nurses is a factor associated with nurses' burnout, } \\
\text { job dissatisfaction and turnover. }\end{array}$ & 3.68 & 0.67 & 181.2 & .000 & 10 & Agree \\
\hline 50 & $\begin{array}{l}\text { Bullying among nurses causes a deterioration in communication and } \\
\text { team work, which affects patients' safety and quality of care. }\end{array}$ & 3.67 & 0.70 & 169.0 & .000 & 11 & Agree \\
\hline \multirow[t]{2}{*}{49} & $\begin{array}{l}\text { Healthcare organizations where bullying is embedded among nurses } \\
\text { have difficulties in retaining new nurses and lose expert nurses. }\end{array}$ & 3.55 & 0.74 & 322.7 & .000 & 12 & Agree \\
\hline & Overall bullying & 4.12 & & & & & Agree \\
\hline
\end{tabular}

Table 6. Independent samples $t$-test for the differences between respondents in their opinions toward each axis according to gender

\begin{tabular}{|c|c|c|c|c|c|}
\hline Axes & Gender & Mean & SD. & $T$-test & $p$ \\
\hline \multirow{2}{*}{ Workplace bullying policy in your hospital } & Male & 27.5111 & 9.07700 & \multirow{2}{*}{0.323} & \multirow{2}{*}{.748} \\
\hline & Female & 27.0518 & 6.83003 & & \\
\hline \multirow{2}{*}{$\begin{array}{l}\text { Nurses' knowledge and skills in handling bullying } \\
\text { situations }\end{array}$} & Male & 38.5556 & 4.34613 & \multirow{2}{*}{2.516} & \multirow{2}{*}{$.012 *$} \\
\hline & Female & 36.6056 & 4.86208 & & \\
\hline \multirow{2}{*}{$\begin{array}{l}\text { Nursing manager's role in handling bullying } \\
\text { situations }\end{array}$} & Male & 33.0000 & 7.29259 & \multirow{2}{*}{1.138} & \multirow{2}{*}{.256} \\
\hline & Female & 31.7410 & 6.74690 & & \\
\hline \multirow{2}{*}{ Bullying } & Male & 44.9556 & 5.86188 & \multirow{2}{*}{-1.260} & \multirow{2}{*}{.209} \\
\hline & Female & 45.9363 & 4.59956 & & \\
\hline
\end{tabular}

$* p<.05$

Table 7. Model of multiple regressions of the factors

\begin{tabular}{llllllll}
\hline Model & $\mathbf{B}$ & $\mathbf{R}$ & $\mathbf{R}^{2}$ & $\mathbf{F}$ & Sig & $\mathbf{T}$ & Sig. \\
\hline Constant & 43.91 & & & & & 16.94 & .000 \\
Workplace bullying policy in your hospital. & .023 & \multirow{2}{*}{184} & \multirow{2}{*}{.034} & \multirow{2}{*}{3.417} & .018 & .49 & .627 \\
Nurses' knowledge and skills in handling bullying situations. & .149 & & & & & 2.28 & .024 \\
Nursing manager's role in handling bullying situations. & $-.133-$ & & & & & -2.58 & .010 \\
\hline
\end{tabular}




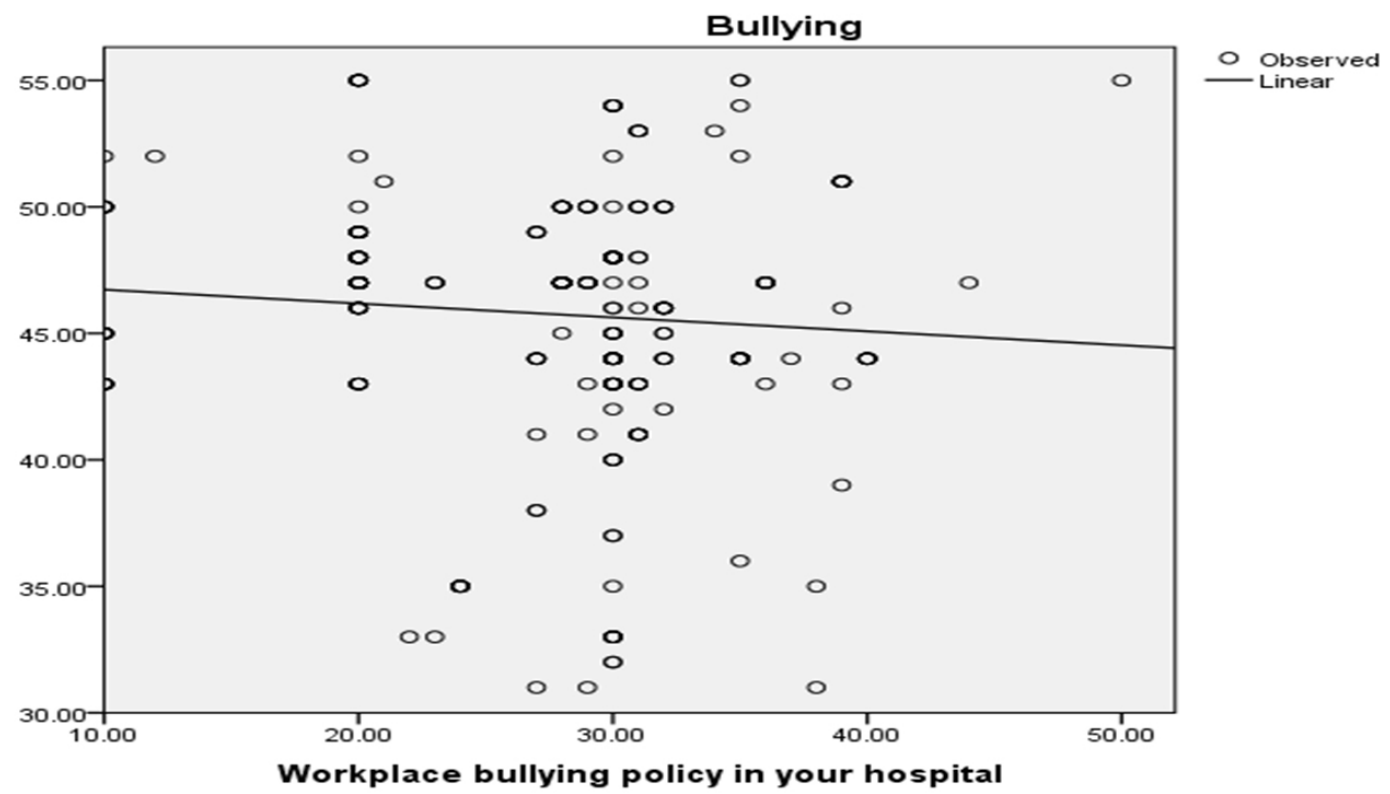

Figure 1. Relationship between the presence of a workplace code of ethics policy to address bullying behaviours and counteracting bullying among nurses in the workplace

The Chi-square values are statistically significant ( $p$-values are less than .05), i.e., there is a significant difference between the expected and observed frequencies for nurses' workplace bullying (dependent) and the workplace bullying policy in the hospital (independent) variables.

2) There is a significant statistical relationship between the nursing manager's role in handling bullying issues and bullying among nurses in the workplace.

The previous table shows the relationship between "Nursing manager's role in handling bullying situations" and "Bullying". We find that the correlation coefficient is 0.086 , which indicates that when the manager's role becomes more passive and destructive, the bullying becomes more embedded in the nurses' workplace. The $p$-value is .141 which is not statistically significant, so we reject the second hypothesis, i.e., there is no statistically significant relationship between the nursing manager's role in handling bullying issues and counteracting bullying among nurses in the workplace. Figure 2 represents such a relationship.

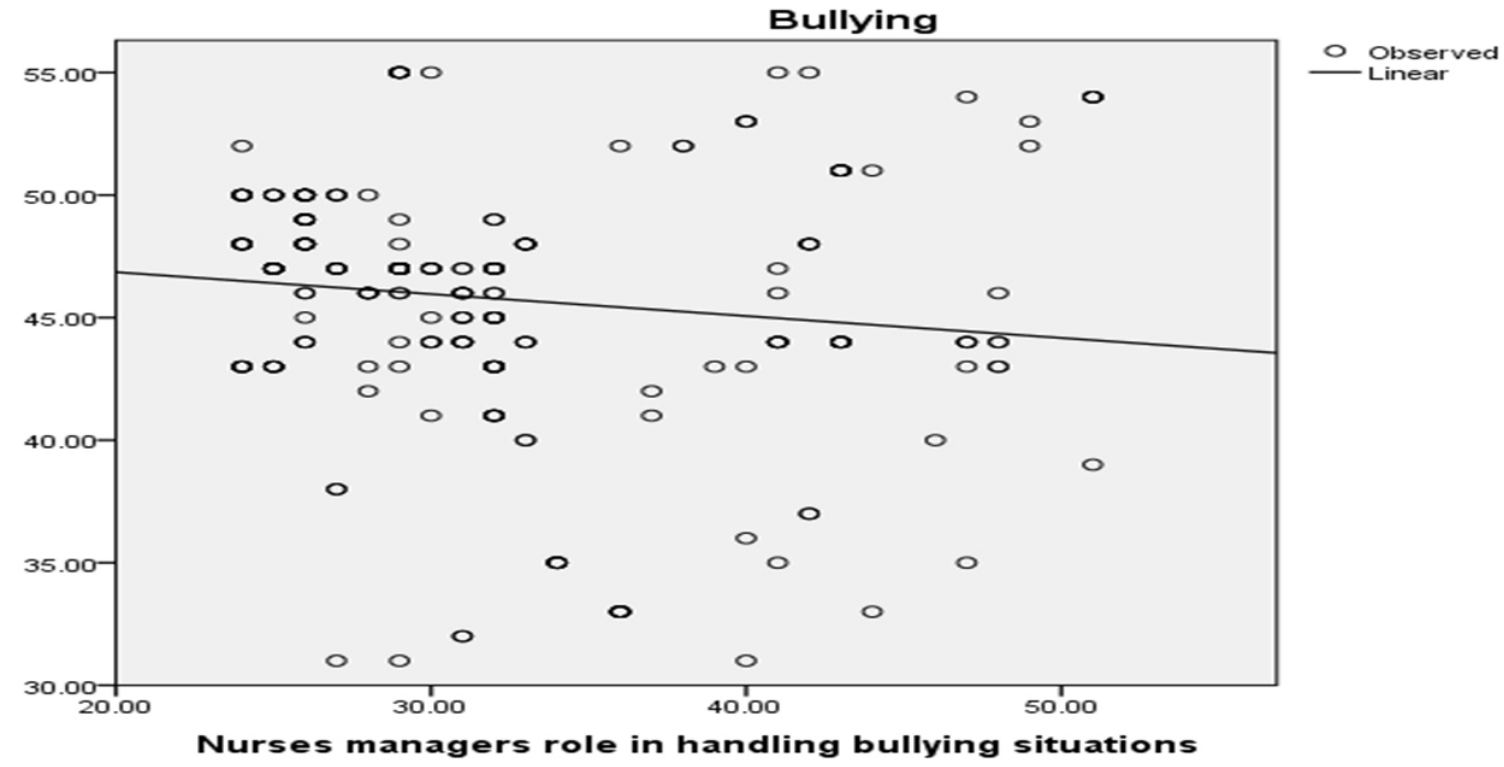

Figure 2. Relationship between the nursing manager's role in handling bullying issues and counteracting bullying among nurses in the workplace 
We find that the Chi-square value is statistically significant ( $p$-value is less than .05), i.e., there is a significant difference between the expected and observed frequencies for nurses' workplace bullying (dependent) and the nursing manager's role in handling bullying situations (independent) variables.

3) There is a significant statistical relationship between the nursing staff's knowledge and skills in dealing with and confronting bullying and its effects and bullying among nurses in the workplace.
The previous table shows the relationship between "Nurses' knowledge and skills in handling bullying situations" and "Bullying". We find that the correlation coefficient is -0.127 which shows that as knowledge and skills improve, bullying declines, and the $p$-value is .029 which is statistically significant, so we accept the third hypothesis, i.e., there is a statistically significant relationship between nurses' knowledge and skills in dealing with and confronting bullying and its effects on bullying among nurses in the workplace. Figure 3 represents such a relationship.

Table 8. Correlation between independent and dependent variables

\begin{tabular}{|c|c|c|c|c|}
\hline & \multicolumn{2}{|c|}{ Pearson correlation } & \multicolumn{2}{|c|}{ Chi-square } \\
\hline & Value & $p$-value & Value & $p$-value \\
\hline $\begin{array}{l}\text { 1-Workplace bullying policy in your hospital } \\
\text { Bullying }\end{array}$ & $-.082 *$ & .159 & $1,430.481$ & .000 \\
\hline $\begin{array}{l}\text { 2-Nursing manager's role in handling bullying situations } \\
\text { Bullying }\end{array}$ & .086 & .141 & $1,343.644$ & .000 \\
\hline $\begin{array}{l}\text { 3-Nurses' knowledge and skills in handling bullying situations } \\
\text { Bullying }\end{array}$ & $-.127 *$ & .029 & $2,202.926$ & .000 \\
\hline
\end{tabular}

$* p<.05$

Also, the Chi-square value is statistically significant ( $p$-value is less than .05), i.e., there is a significant difference between the expected and observed frequencies for nurses' workplace bullying (dependent) and nurses' knowledge and skills in handling bullying situations (independent) variables.

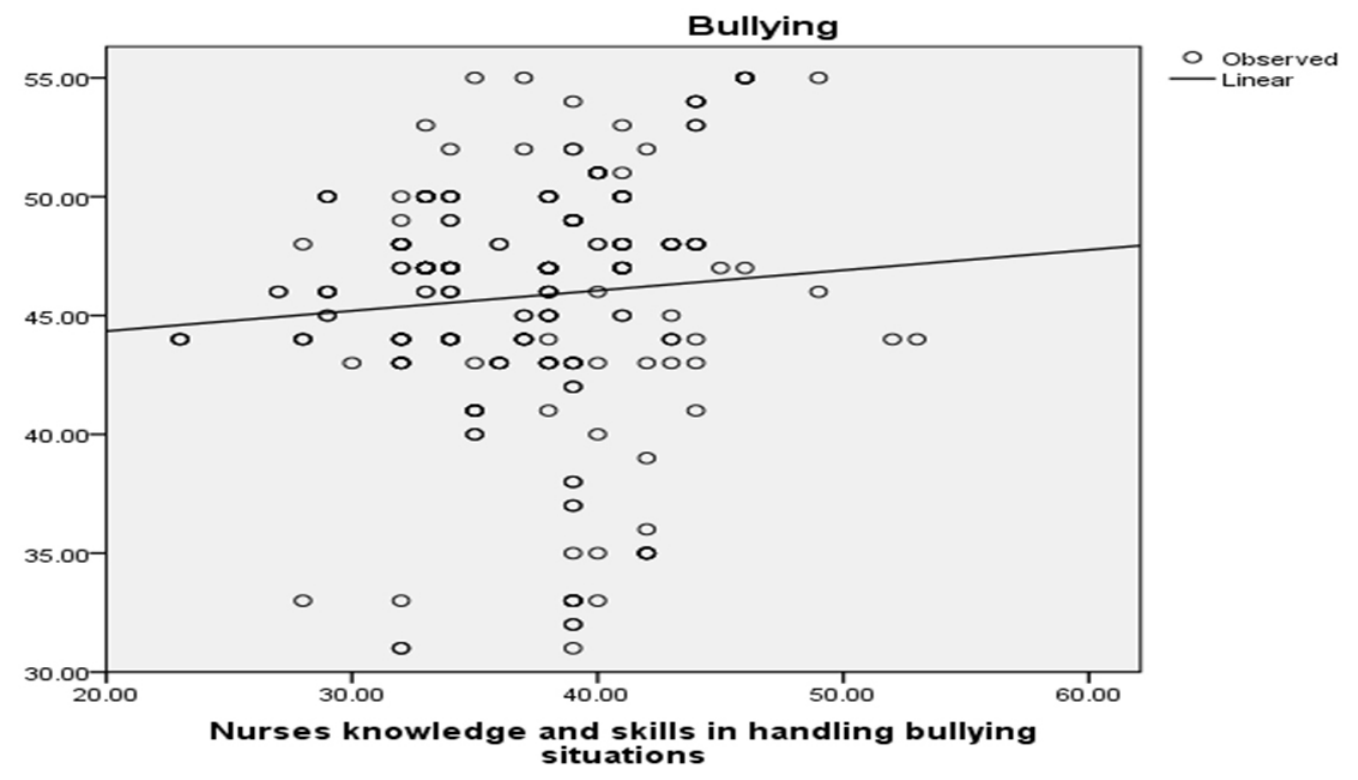

Figure 3. Relationship between nurses' knowledge and skills in dealing with and confronting bullying and its effects on bullying among nurses in the workplace

\section{RESEARCH DISCUSSION}

The present study was conducted on multicultural population in a Middle Eastern country's HCO which is directed by

Published by Sciedu Press international standardized management system and that is accredited by Joint Commission International for meeting the international health care quality standards for organization 
management. The study analysis finds the majority of individuals are female $(84.9 \%)$, from the Philippines $(48.6 \%)$, are working full time $(96.6 \%)$, have a Bachelor's degree in nursing $(70.6 \%)$, hold the position of staff nurse $(74 \%)$, have between 3 to 6 years' experience in nursing (39.9\%) and have been in their current position less than 3 years $(33.7 \%)$ The managers' response rate is $91.7 \%$.

The nurses' gender influences their knowledge and skills in handling bullying situations. As male nurses have better knowledge and skills in how to counteract bullying, they are more confident in confronting bullies. While gender differences have no influence on respondents' opinions about a workplace bullying policy and the manager's role in counteracting bullying, and bullying in the nurses' workplace, there are significant differences between respondents of different nationalities in their opinion toward the presence of a workplace bullying policy and the role nursing managers play in handling bullying situations, and the bullying. On the other hand, differences in nationalities did not affect nurses' opinions on the axes "Nurses' knowledge and skills in handling bullying situations". Nurses who work part time are more confident about their knowledge and skills in counteracting bullying in the workplace than those who work full time.

Nurses' qualifications influence their opinions regarding the presence of a workplace bullying policy in their hospital and the nursing manager's role in handling bullying and its effect on bullying in the workplace. However, different qualifications have no influence on nurses' opinions regarding the importance of nurses' knowledge and skills as a means of counteracting bullying in the workplace. The number of years of experience in nursing affects nurses' opinions of the presence of a workplace bullying policy, the nursing manager's role in handling bullying situations and bullying in the workplace, although, it does not affect their opinions toward the importance and influence of nurses' knowledge and skills in handling bullying in the workplace. The number of years spent in the current position has a significant influence on nurses' responses to the presence of a workplace bullying policy, nurses' knowledge and skills and the nursing manager's role in handling bullying situations, although, this has no effect on their responses to the presence, and effects of workplace bullying.

Altogether, $56.4 \%$ of participants are not sure or disagree that there is a code of conduct policy to address bullying available in the hospital, and $53.4 \%$ of respondents disagree that the policy is accessible, and that there is an independent bullying policy and bullying victims support group. The study results prove the lack of bullying policies in HCOs contribute to escalating bullying and its consequences, results which are similar to other studies. ${ }^{[52,56,57]}$ A global move led by the WHO initiated guidelines for all countries' HCOs to use to assist in counteracting healthcare workplace bullying behaviours, ${ }^{[55]}$ but inconsistencies in nurses' awareness of the policy and a lack of concise and clear detailed information, contribute directly to the prevalence of bullying among $\mathrm{HCO}$ staff. $[23,59,60]$

The majority (63\%) of respondents agree that bullying can be prevented, and an overwhelming majority (86.4\%) strongly agree that it is necessary to have formal structured education and training programs to develop nurses' knowledge and skills to assist them in dealing with bullying and its issues in the workplace, ${ }^{[64,67,75]}$ to improve the role of managers so that they are proactive in mitigating uncivil behaviours ${ }^{[36]}$ and to give nurses the opportunity to evaluate their nurse colleagues by the means of mandatory annual peer reviews.

Managers' roles are identified by the study sample as being passive, and sometimes destructive, with nurses not reporting bullying incidents to their managers due to fear of the consequences, which results in under-reporting of bullying and a decrease in nurses' faith in managerial ability to handle it. Consequently, bullying has become a persistent problem in the nurses' workplace. ${ }^{[20,62]}$ Managers are key players in mitigating bullying behaviours in nursing workplaces ${ }^{[76]}$ as their managerial and leadership skills could provide a model for all staff nurses to foster a culture of respect. Managers' roles are wide-reaching as they report to higher management and facilitate policy implementation among staff nurses. ${ }^{[36,62]}$ Participants strongly agreed by a majority of $92.2 \%$ that bullying could take several forms such as intimidating gestures, undermining acts, verbal affront, improper work interference, withholding information, social isolation, smearing professional or personal reputations, and being given an unmanageable work load. ${ }^{[21]}$ For that reason, the involvement of upper management is crucial. ${ }^{[36,45,48,50,61,62]}$ Participants also agree that bullying is mistreatment intended to cause harm to the targeted nurse, ${ }^{[39]}$ resulting in an unhealthy work environment. The majority of participants (87.8\%) strongly agree that bullying could be a misuse of a position of power, such as managerial bullying of the staff, and that bullying could become normalized and viewed as legitimate within the organizational culture. ${ }^{[45,48,52]}$ As a result, HCO higher management is implicated in setting rules and regulations to counteract bullying behaviour and evaluating their effectiveness. $^{[33]}$

Participants also agree that bullying behaviours have a negative impact on the individual nurse, patient care, safety, patients' outcomes and staff nurse satisfaction, may lead to rising tensions in patient care areas, cause nursing staff to 
reduce their level of performance and lead to the loss of expert nurses, therefore affecting the organization in terms of increasing operational costs. ${ }^{[5,44,53,54]}$

\section{RESEARCH CONCLUSIONS}

The research findings are of importance to nursing management. The study disclosed that HCO policies that address bullying behaviours and the role of managers had no significant effect on counteracting bullying behaviours among the nurses sampled in this study. On the other hand, development and improvement of nurses' knowledge and skills in counteracting bullying may have a positive influence in reducing bullying. Although workplace bullying was identified by participants to be a significant negative influence on the individual nurse, teamwork, patient care and outcomes, and the organization as a whole, managers' roles were not optimal in counteracting bullying among nurses as the nurses were not aware of the existing bullying policy, and had no trust in the system or in the management's ability to deal with bullying issues. Nurses' workplace bullying behaviours can be managed and eradicated by the means of collaboration of the three parties: nursing managers, policy, and nurses'

\section{REFERENCES}

[1] World Health Organization. Five Keys to Healthy Workplace. 2017. Available from: http://www.who.int/occupational_health/ healthy_workplaces [Accessed 25 May 2017].

[2] World Health Organization. Mental health: strengthening our response. 2016. Available from: http://www . who.int/entity/m ediacentre/factsheets/fs220/en/ [Accessed 4 April 2017].

[3] Reknes I, Pallesen S, Magerøy N, et al. Exposure to bullying behaviors as a predictor of mental health problems among Norwegian nurses: results from the prospective SUSSH-survey. International Journal of Nursing Studies. 2014; 51(3): 479-487. PMid:23891534 https://doi.org/10.1016/j.ijnurstu.2013.06.017

[4] Morrissey J. Encyclopedia of errors. Growing database of medication errors allows hospitals to compare their track records with facilities nationwide in a nonpunitive setting. Modern Healthcare. 2003; 33(12): 40-42.

[5] Rosenstein AH, O'daniel M. Disruptive Behavior \& Clinical Outcomes: Perceptions of Nurses \& Physicians: Nurses, physicians, and administrators say that clinicians' disruptive behavior has negative effects on clinical outcomes. Nursing Management. 2005; 36(1): 18-28. https://doi.org/10.1097/00006247-200501000-00008

[6] World Health Organization. Practical tools for managing risks at the workplace. 2009.

[7] American Nurses Association. Position statement on incivility, bullying, and workplace violence. Nursing World Web site. 2015. Available from: http://www.nursingworld.org/Bullying-Workp lace-Violence [Accessed 12 June 2017]

[8] Wyatt RM. Revisiting disruptive and inappropriate behavior: five years after standards introduced. Jt Comm Physician Blog. 2014; 1-3.

[9] Broome BS, Williams-Evans S. Bullying in a caring profession: Reasons, results, and recommendations. Journal of Psychosocial Nursing and Mental Health Services. 2011; 49(10): 30-35. PMid:21919429 https://doi.org/10.3928/02793695-20110831-02 knowledge and skills.

\section{Research recommendations}

This research has considerable implications for higher nursing management in counteracting bullying among nurses. They have a fundamental role in counteracting bullying, for example by setting policy and conducting organization-wide surveys to study nurses' job satisfaction, including nurse-tonurse relationships satisfaction, and imposing nursing peer reviews as a mandatory annual appraisal for each nurse. They should also initiate formal systems to report behavioural issues among healthcare staff and encourage nurses to report behavioural issues, formulate a committee that is responsible for responding to and dealing with behavioural issues among the organization's staff, and enforce a behavioural issues educational program for nursing managers and nursing staff that includes awareness of the hospital's bullying policy. This should also include setting organizational goals to maintain staff dignity in the workplace.

\section{CONFlicts OF INTEREST Disclosure}

The authors declare that there is no conflict of interest.
[10] Safe Work Australia. How to manage work health and safety risks: Code of practice. 2011.

[11] Australian Nursing and Midwifery Federation. Bullying in the Workplace. 2015.

[12] World Health Organization. PRIMA-EF: guidance on the European framework for psychosocial risk management: a resource for employer and worker representatives. 2008. Available from: http://apps.who.int/iris/bitstream/10665/4396 6/4/9783882616477_ger.pdf [Accessed 21 June 2017]

[13] Australian Nursing and Midwifery Federation (Victorian Branch) (ANMF Vic). WORKPLACE BULLYING. 2013. Available from: http://www.anmfvic.asn.au/ /media/files/anmf/vic $\% 2$ Obranch\%20policies\%20and\%20position\%20statements/w orkplace\%20bullying.pdf [Accessed 17 May 2017]

[14] Ministry of Health (MOH). Statistical yearbook. 2015. Available from: https://www.moh.gov.sa/en/Ministry/Statistics/ book/Pages/default.aspx [Accessed 11 April 2017]

[15] Yıldırım D. Bullying among nurses and its effects. International Nursing Review. 2009; 56(4): 504-511. PMid:19930081 https: //doi.org/10.1111/j.1466-7657.2009.00745.x

[16] Lewis MA. Nurse bullying: organizational considerations in the maintenance and perpetration of health care bullying cultures. Journal of Nursing Management. 2006; 14(1): 52-58. PMid:16359446 https://doi.org/10.1111/j.1365-2934.2005.00535.x

[17] Duffy E. Horizontal violence: A conundrum for nursing. Collegian. 1995; 2(2): 512-917. https://doi .org/10.1016/S1322-7 696 (08) 60093-1

[18] Jackson D, Clare J, Mannix J. Who would want to be a nurse? Violence in the workplace-a factor in recruitment and retention. Journal of Nursing Management. 2002; 10(1): 13-20. https ://doi.org/ $10.1046 / \mathrm{j} .0966-0429.2001 .00262 \cdot \mathrm{x}$

[19] Hutchinson M, Vickers M, Jackson D, et al. Workplace bullying in nursing: towards a more critical organisational perspective. 
Nursing Inquiry. 2006; 13(2): 118-126. PMid:16700755 https: //doi.org/10.1111/j.1440-1800.2006.00314.x

[20] Hutchinson M, Wilkes L, Jackson D, et al. Integrating individual, work group and organizational factors: Testing a multidimensional model of bullying in the nursing workplace. Journal of Nursing Management. 2010; 18(2): 173-181. PMid:20465745 https://doi.org/10.1111/j.1365-2834.2009.01035.x

[21] Hutchinson M, Vickers MH, Wilkes L, et al. A typology of bullying behaviours: the experiences of Australian nurses. Journal of Clinical Nursing. 2010; 19(15-16): 2319-2328.

[22] McKenna BG, Smith NA, Poole SJ, et al. Horizontal violence: Experiences of registered nurses in their first year of practice. Journal of AdvancedNursing. 2003; 42(1): 90-96. https://doi.org/10 $.1046 / j .1365-2648.2003 .02583 . x$

[23] Parker KM, Harrington A, Smith CM, et al. Creating a NurseLed Culture to Minimize Horizontal Violence in the Acute Care Setting: A Multi-Interventional Approach. Journal for Nurses in Professional Development. 2016; 32(2): 56-63. PMid:26985749 https://doi.org/10.1097/NND.0000000000000224

[24] Griffin M. Teaching cognitive rehearsal as a shield for lateral violence: An intervention for newly licensed nurses. The Journal of Continuing Education in Nursing. 2004; 35(6): 257-263. PMid: 15584678

[25] Roberts SJ. Lateral violence in nursing: a review of the past three decades. Nursing Science Quarterly. 2015; 28(1): 36-41. PMid:25520463 https://doi.org/10.1177/08943184145586 14

[26] Alspach G. Lateral Hostility Between Critical Care Nurses A Survey Report. 2008.

[27] D'ambra AM, Andrews DR. Incivility, retention and new graduate nurses: an integrated review of the literature. Journal of Nursing Management. 2014; 22(6): 735-742. PMid:23927565 https: //doi.org/10.1111/jonm. 12060

[28] Asi Karakaş S, Okanli AE. The effect of assertiveness training on the mobbing that nurses experience. Workplace Health \& Safety. 2015 63(10): 446-451. PMid:26242741 https://doi.org/10.1177/ 2165079915591708

[29] Rogers-Clark C, Pearce S, Cameron M. Management of disruptive behaviour within nursing work environments: a comprehensive systematic review of the evidence. JBI Database of Systematic Reviews and Implementation Reports. 2009; 7(15): 615-678. https://doi.org/10.11124/01938924-200907150-00001

[30] Longo J. Combating disruptive behaviors: Strategies to promote a healthy work environment. The Online Journal of Issues in Nursing. 2010; 15(1).

[31] Rocker CF. Addressing nurse-to-nurse bullying to promote nurse retention. Online Journal of Issues in Nursing. 2008; 13(3).

[32] Murray JS. Workplace bullying in nursing: A problem that can't be ignored. Medsurg Nursing. 2009; 18(5): 273. PMid:19927962

[33] Johnson SL, Rea RE. Workplace bullying: Concerns for nurse leaders. Journal of Nursing Administration. 2009; 39(2): 84-90. PMid:19190425 https://doi.org/10.1097/NNA.0b013e3181 $95 \mathrm{a} 5 \mathrm{fc}$

[34] Broome BS, Williams-Evans S. Bullying in a caring profession: Reasons, results, and recommendations. Journal of Psychosocial Nursing and Mental Health Services. 2011; 49(10): 30-35. PMid:21919429 https://doi.org/10.3928/02793695-20110831-02

[35] Etienne E. Exploring workplace bullying in nursing. Workplace Health \& Safety. 2014; 62(1): 6-11. PMid:24571049 https : //doi . org $/ 10.1177 / 216507991406200102$

[36] Strandmark KM, Rahm G, Wilde Larsson B, et al. Preventive strategies and processes to counteract bullying in health care settings: Focus Group Discussions. Issues in Mental Health Nursing. 2017;
38(2): 113-121. PMid:27937001 https://doi.org/10.1080/01 612840.2016 .1253805

[37] World Health Organization. Framework guidelines for addressing workplace violence in the health sector. 2017. Available from: http://www. who.int/violence_injury_prevention /violence/activities/workplace/en/ [Accessed 14 July 2017]

[38] Dalton D. Bullying in the Healthcare Industry. Journal of Emergency Medical Services. 2016. Available from: http://www . jems. com/ems-insider/articles/2016/0 8/bullying-in-the-healthcare-industry.html [Accessed 18 May 2017]

[39] Einarsen S, Skogstad A, Rørvik E, et al. Climate for conflict management, exposure to workplace bullying and work engagement: a moderated mediation analysis. The International Journal of Human Resource Management. 2016; 1-22.

[40] Elena Losa Iglesias M, Becerro de Bengoa Vallejo R. Prevalence of bullying at work and its association with self-esteem scores in a Spanish nurse sample. Contemporary Nurse. 2012; 42(1): 2-10. PMid:23050566 https://doi. org/10.5172/conu . 2012.42.1 .2

[41] Quine L. Workplace bullying in nurses. Journal of Health Psychology. 2001; 6(1): 73-84. PMid:22049239 https ://doi.org/10.1177/ 135910530100600106

[42] Alswaid E. Workplace Bullying Among Nurses in Saudi Arabia: An Exploratory Qualitative Study. Massey University. 2014; 1-129 (Master thesis).

[43] Berry PA, Gillespie GL, Fisher BS, et al. Psychological distress and workplace bullying among registered nurses. OJIN: The Online Journal of Issues in Nursing. 2016; 21(3): 4.

[44] Evans D. Categorizing the magnitude and frequency of exposure to uncivil behaviors: a new approach for more meaningful interventions. Journal of Nursing Scholarship. 2017; 49(2): 214-222. PMid:28079970 https://doi.org/10.1111/jnu. 12275

[45] Vessey JA, DeMarco RF, Gaffney DA, et al. Bullying of staff registered nurses in the workplace: a preliminary study for developing personal and organizational strategies for the transformation of hostile to healthy workplace environments. Journal of Professional Nursing. 2009; 25(5): 299-306. PMid:19751935 https: //doi.org/10.1016/j.profnurs.2009.01.022

[46] Pinar T, Acikel C, Pinar G, et al. Workplace violence in the health sector in Turkey: a national study. Journal of Interpersonal Violence. 2017; 32(15): 2345-2365. PMid:26124224 https ://doi.org/10 $.1177 / 0886260515591976$

[47] Mayhew C, Chappell D. Workplace violence in the health sector-a case study in Australia. Safety. 2003; 19: 6.

[48] Hutchinson M, Vickers MH, Wilkes L, et al. "The worse you behave, the more you seem, to be rewarded": bullying in nursing as organizational corruption. Employee Responsibilities and Rights Journal. 2009; 21(3): 213-229. https://doi.org/10.1007/s10672-009 $-9100-z$

[49] Reknes I, Pallesen S, Magerøy N, et al. Exposure to bullying behaviors as a predictor of mental health problems among Norwegian nurses: results from the prospective SUSSH-survey. International Journal of Nursing Studies. 2014; 51(3): 479-487. PMid:23891534 https://doi.org/10.1016/j.ijnurstu.2013.06.017

[50] Myers G, Cote-Arsenault D, Worral P, et al. A cross-hospital exploration of nurses' experiences with horizontal violence. Journal of Nursing Management. 2016; 24(5): 624-633. PMid:26860341 https://doi.org/10.1111/jonm. 12365

[51] Chapman R, Styles I. An epidemic of abuse and violence: nurse on the front line. Accident and Emergency Nursing. 2006; 14(4): 245 
249. PMid:17064902 https://doi.org/10.1016/j. aaen. 200 6.08 .004

[52] Blackstock S, Harlos K, Macleod ML, et al. The impact of organisational factors on horizontal bullying and turnover intentions in the nursing workplace. Journal of Nursing Management. 2015; 23(8): 1106-1114. PMid:25370741 https://doi.org/10.1111/ jonm. 12260

[53] Gates DM, Gillespie GL, Succop P. Violence against nurses and its impact on stress and productivity. Nursing Economics. 2011; 29(2): 59. PMid:21667672

[54] Koh WMS. Management of work place bullying in hospital: A review of the use of cognitive rehearsal as an alternative management strategy. International Journal of Nursing Sciences. 2016; 3(2): 213-222. https://doi.org/10.1016/j.ijnss.2016.04.010

[55] Srabstein JC, Leventhal BL. Prevention of bullying-related morbidity and mortality: a call for public health policies. Bulletin of the World Health Organization. 2010; 88(6): 403-404. PMid:20539848 https://doi.org/10.2471/BLT.10.077123

[56] Berry PA, Gillespie GL, Gates D, et al. Novice nurse productivity following workplace bullying. Journal of Nursing Scholarship. 2012; 44(1): 80-87. PMid:22339938 https://doi.org/10.1111/j.15 47-5069.2011.01436.x

[57] Fang L, Huang SH, Fang SH. Workplace bullying among nurses in South Taiwan. Journal of clinical nursing. 2016; 25(17-18): 24502456. PMid:27229942 https://doi.org/10.1111/jocn. 13260

[58] American Nurses Association (ANA). ANA Panel Aims to Prevent Violence, Bullying in Health Care Facilities. 2015.

[59] Johnson SL, Boutain DM, Tsai JHC, et al. An investigation of organizational and regulatory discourses of workplace bullying. Workplace Health \& Safety. 2015; 63(10): 452-461. PMid:26223898 https://doi.org/10.1177/2165079915593030

[60] Johnson SL, Boutain DM, Tsai JHC, et al. An exploration of managers' discourses of workplace bullying. In Nursing Forum. 2015; 50(4): 265-273. PMid:25597260 https : //doi .org/10.1111/nu f. 12116

[61] Farrell GA, Shafiei T. Workplace aggression, including bullying in nursing and midwifery: a descriptive survey (the SWAB study). International Journal of Nursing Studies. 2012; 49(11): 1423-1431. PMid:22770947 https://doi.org/10.1016/j.ijnurstu. 201 2.06 .007

[62] Kaiser JA. The relationship between leadership style and nurse-tonurse incivility: turning the lens inward. Journal of Nursing Management. 2017; 25(2): 110-118. PMid:27896878 https://doi.org/ 10.1111/jonm. 12447

[63] Ovayolu Ö, Ovayolu N, Karadag G. Workplace bullying in nursing. Workplace Health \& Safety. 2014; 62 (9): 370-374. PMid:25102477 https://doi.org/10.3928/21650799-20140804-04

[64] Cheung T, Yip PS. Workplace violence towards nurses in Hong Kong: prevalence and correlates. BMC public health. 2017; 17(1): 196. PMid:28196499 https://doi .org/10.1186/s12889-017 $-4112-3$
[65] Lin YR, Shiah IS, Chang YC, et al. Evaluation of an assertiveness training program on nursing and medical students' assertiveness, self-esteem, and interpersonal communication satisfaction. Nurse Education Today. 2004; 24(8): 656-665. PMid:15519449 https://doi.org/10.1016/j.nedt.2004.09.004

[66] Arnetz JE, Arnetz BB. Implementation and evaluation of a practical intervention programme for dealing with violence towards health care workers. Journal of Advanced Nursing. 2000; 31(3): 668-680. https://doi.org/10.1046/j.1365-2648.2000.01322.x

[67] Oh H, Uhm DC, Yoon YJ. Factors affecting workplace bullying and lateral violence among clinical nurses in Korea: descriptive study. Journal of Nursing Management. 2016; 24(3): 327-335. PMid:26172343 https://doi .org/10.1111/jonm.12324

[68] Yun S, Kang J, Lee YO, et al. Work environment and workplace bullying among Korean intensive care unit nurses. Asian Nursing Research. 2014; 8(3): 219-225. https://doi.org/10.1016/j.anr. 2014.07 .002

[69] Ceravolo DJ, Schwartz DG, FOLTZ-RAMOS KM, et al. Strengthening communication to overcome lateral violence. Journal of Nursing Management. 2012; 20(5): 599-606. PMid:22823215 https: //doi.org/10.1111/j.1365-2834.2012.01402.x

[70] Moxham L. Nurse Education, Research and Evidence-Based Practice. In Berman SJ, Snyder T, Levett-Jones M, Hales N, Harvey Y, Luxford L, Moxham T, Park B, Parker K, Stanley D. (Eds.) Fundamentals of Nursing. 2012. Frenchs Forest, Sydney: Pearson Australia.

[71] Sripichyakan K, Thungpunkum P, Supavititpatana B. Workplace violence in the health sector-A case study in Thailand. ILO/ICN/WHO/PSI Joint program on workplace violence in the health sector, Geneva. 2003.

[72] Xing K, Jiao M, Ma H, et al. Physical violence against general practitioners and nurses in Chinese township hospitals: a cross-sectional survey. PLoS One. 2015; 10(11): e0142954. PMid:26571388 https : //doi.org/10.1371/journal.pone.0142954

[73] Aytac S, Bozkurt V, Bayram N, et al. Workplace violence: a study of Turkish workers. International Journal of Occupational Safety and Ergonomics. 2011; 17(4): 385-402. PMid:22152504 https://doi.org/10.1080/10803548.2011.11076902

[74] El-Gilany AH, El-Wehady A, Amr M. Violence against primary health care workers in Al-Hassa, Saudi Arabia. Journal of Interpersonal Violence. 2010; 25(4): 716-34. PMid:19494243 https: //doi.org/10.1177/0886260509334395

[75] Gilbert RT, Hudson JS, Strider D. Addressing the elephant in the room: nurse manager recognition of and response to nurse-to-nurse bullying. Nursing Administration Quarterly. 2016; 40(3): E1-1. PMid:27259133 https://doi.org/10.1097/NAQ. 0000000000 000175

[76] Skarbek AJ, Johnson S, Dawson CM. A phenomenological study of nurse manager interventions related to workplace bullying. Journal of Nursing Administration. 2015; 45(10): 492-7. PMid:26425973 https://doi.org/10.1097/NNA.0000000000000240 